\title{
Body Image concerns of Male Rugby Players, with specific focus on Muscularity and Body Fat
}

\author{
Mills $\mathrm{CD}^{*}$ and Giles GJ
}

Faculty of Business, Computing and Applied Sciences, University of Gloucestershire, Gloucester, UK

${ }^{*}$ Corresponding author: Mills CD, Faculty of Business, Computing and Applied Sciences, University of Gloucestershire, Gloucester, UK, E-mail: clairem@glos.ac.uk

Citation: Mills CD, Giles GJ (2017) Body Image concerns of Male Rugby Players, with specific focus on Muscularity and Body Fat. J Obes Overweig 3(1): 103. doi: 10.15744/2455-7633.3.103

Received Date: January 19, 2017 Accepted Date: May 16, 2017 Published Date: May 18, 2017

\begin{abstract}
Introduction: Despite the high numbers of participants in both rugby league and union, literature on body image of male rugby players is somewhat limited. However researchers have theorized that the exercise adopted by males may reflect different levels of dissatisfaction, especially in activities that require a large body build, or lean aesthetic physique [1]. Therefore, this study aimed to explore the prevalence of body (dis)satisfaction in terms of muscularity and body fat, and secondly to identify areas of the body that require a change (in either increase/decrease in musculature or body fat) to improve body image.

Method: A volunteer sample of $n=93$ male University Rugby Union and League participants between the ages $18-25$ years of age were targeted via social media. An online survey was taken using a mixture of multiple choices and Likert scaled questions from an adaptation of the Bodybuilders Image Grid (BIG-O) [2]. Participants identified areas for increased muscularity and areas of the body for body fat changes and statistical analyses used to assess the difference between current and ideal body size.

Results: Participants were mostly dissatisfied (49.46\%) with their current body image. All participants highlighted at least one muscle group for increased muscularity. $88.44 \%$ of participants desired no increase in body fat, whilst $86.41 \%$ wished to reduce body fat in at least one area. Pectorals $(50.52 \%)$, quadriceps $(43.01 \%)$ and abdominals $(34.41 \%)$ were the most common areas for increased muscle mass. Main areas targeted for reduced body fat were stomach (86.02\%), chest (39.78\%) and back $(24.73 \%)$.

Conclusion: Although body image is complex and easily influenced, the majority of participant's were dissatisfied with their body and desired a reduction in body fat levels and increased muscularity. Recommendations would allow researchers to compare body (dis) satisfaction between those with a performance focus and those focused on societies ideal. Furthermore, to recruit varying rugby playing standards, such as international and club level players and compare if there are differences in body (dis)satisfaction.
\end{abstract}

Keywords: Body Image; Muscularity; Body Fat; Body (Dis)Satisfaction; Rugby

\section{Introduction}

Body image is a subjective issue specific to each individual. It is the picture of your own body that you form within your head, the evaluation of body size, weight, shape and muscularity and the thoughts and feelings that are associated with this [3]. There is no simple link that can be drawn from ones experiences of their body and what they perceive of it [3]. Body image is complex and can be easily influenced; in fact it has even been referred to as elastic by nature due to its ability to be so easily influenced within a short time frame [4]. Parents, peers, the media and sport are just a small number of examples of what can, and do influence body image [5]. Recent studies have identified that two thirds of all adults in the UK suffer from negative body image [6]. An issue that the Government has even shown concern towards due to the damage it can cause to mental wellbeing, referring to conditions like anorexia nervosa, bulimia and muscle dysmorphia [7]. Unfortunately it is not just adults that suffer, boys as young as eight are now concerned with being acceptably $\mathrm{V}$ shaped, with a well-developed chest and slim waist [3]. Thus promoting the importance of increased research, knowledge and prevention work to reduce the UK's body dissatisfaction levels are vital.

\section{Media's Outlook on Man, and its Influence on Shaping the Male Physique}

Social experience and media play important roles in forming both perceived and ideal body image. Leit, Gray and Pope [8] explored the power of media imagery and found that students exposed to muscular images showed a significantly greater discrepancy between their own perceived muscularity and the level of muscularity that they ideally wanted. However it is dependent on the susceptibility of an individual to such imagery [9]. Gross [10] was one of the first to highlight the changes in media towards the young, lean and muscular male physiques that had been profiled as the new ideal male of the 1980's. Gross [10] discovered that 
commercials for diet soda and cosmetics were beginning to be cast with and target males, roles previously seen as too feminine just a few years ago. Since then the use of males in advertisement has continued to grow. However in recent years the media has begun to exploits new forms of digital modification, further widening the gap between images seen in the media and those that are achievable [11]. Action figure research based on proportional size and scale of limbs and muscle groups have found that over a period of 25 years figures have continued to become more muscular [12]. A similar correlation was also found in research conducted by Leit $e t$ al. [13] and Lanzieri and Cook [14]. Over a period of 25 years a number of magazines found that those targeting men have seen a reduction in overall body fat but most importantly a substantial increase in musculature, with the chest, upper arm and abdomen having a stronger emphasis [15].

\section{Sectional Analysis of Body Image}

Today in the $21^{\text {st }}$ century, the muscular male ideal still exists, but for quite different reasons. Strength and size was originally desired for the labour intensive times of the past, now it is said to be down to the determination and effort needed to train and achieve such a physique [11]. On the other hand Leit $e t$ al. [8] believe that these changes could be down to the muscular physique playing a more distinguishing role in gender differentiation. It is feasible that this new found importance may be a reaction to women gaining equality [8], with males trying to rebalance their dominance by increasing size and strength differences between sexes. Either way, many males are said to be concerned with the size and shape of their chest, which has a perceived importance in displaying masculinity [16]. Many studies looking at the desire for muscularity have concluded that males are just as likely, if not more likely to want to increase their overall body mass than reduce it, but have failed to distinguish whether this increase is desired in body fat, muscle tissue or both [17,18]. However, Pope, et al. [19] discovered that on average their male participants wanted 35lbs more muscle mass, suggesting the desire was for muscularity. There is also limited academic research on sectional analysis of body image, with little known about problematic muscle groups associated with body dissatisfaction. Sectional analysis refers to a more specific outlook on body image concerns, and focuses on sectioned areas of the body and the major muscle groups within the body. Franzoi and Shields [20] were one of the first to investigate and found that the upper body emphasised its perceived importance in forming a healthy body image amongst men. Furthermore, Hoyt and Kogan [15] results confirmed that men are most dissatisfied with their chest, upper arms, and abdomen. More recently a poll carried out by Jacamo.com highlighted in The Huffington Post [21] found that 54\% of men dislike their stomachs, whilst one in seven (14\%) wished they had bigger pectorals.

\section{Sport Influence on Male Body Image}

Sport is believed to create a context for discussing body image, enabling males to make favourable social comparisons about their size [22]. For instance results from interviews carried out on 40 adolescent males found that attributes that males liked about their bodies were synonymous with those associated with success in sport [22]. Indeed, this evidence indicated that athletes have a more positive body image than non-athletes [23] and those male athletes are largely satisfied with their bodies [24]. However, researchers have theorised that the exercise adopted by males may reflect different levels of dissatisfaction, especially in activities that require a large body build, or lean aesthetic physique [5]. Be that as it may, evidence exists that suggest sporting males are highly critical of their bodies $[25,26]$.

\section{Rugby's Influence on Male Body Image}

Rugby Union and League is one of the most popular sports played by young men in England and Sport England [27] indicated that 264,900 people were involved in organised Rugby in England alone. Whilst these figures do not include all that are involved, it may help to quantify the number of those who may be affected by body image concerns influenced by the increasingly physical game. Pringle and Markula [28] found that the sport of rugby holds a particularly privileged sociocultural position. Although this research was conducted in New Zealand where rugby is the national sport, it's also argued that rugby holds a similar significance within English culture. Such a privilege helps dominate the sports media [29] whilst influencing gender formations [30]. Pringle and Markula [28] also discovered that rugby participation was a vital normalizing practice where the bodies of teenage boys were marked appropriately masculine. In contrast those who did not excel in rugby saw themselves unsuitably masculine and engaged in weight training to increase size and gain respect [28]. Thus further suggesting the importance of both rugby and size as a means of gender processing and the construction of masculinity. Interestingly findings of this nature seem to be age specific; initially rugby is a game to be played by all men to conform to the traditional "manliness" [31]. However, with age rugby becomes a sport of the select few, those that have the skills, confidence, size and speed to match the physicality of the professional game [28].

Research from Olds [32] looked to justify rugby's increased physicality through investigating the changes to both body shape and size of high level rugby players over the past century (1900-2000). Olds [32] results show that the average player had gained 2.6kg of body mass per decade, which was significantly higher than that of general population young males. Sedeaud et al. [34] also found that between 1987 and 2007 high level forwards and backs had become 6.63kg and 6.68kg heavier respectively. This increase can also be seen in England's national team displayed in Figure 1. Findings also suggested a change in actual body shape with less endomorphic ( -0.3 units per decade) and less ectomorphic ( -0.4 units per decade) but more mesomorphic $(+1.1$ units per decade) than before [32]. 


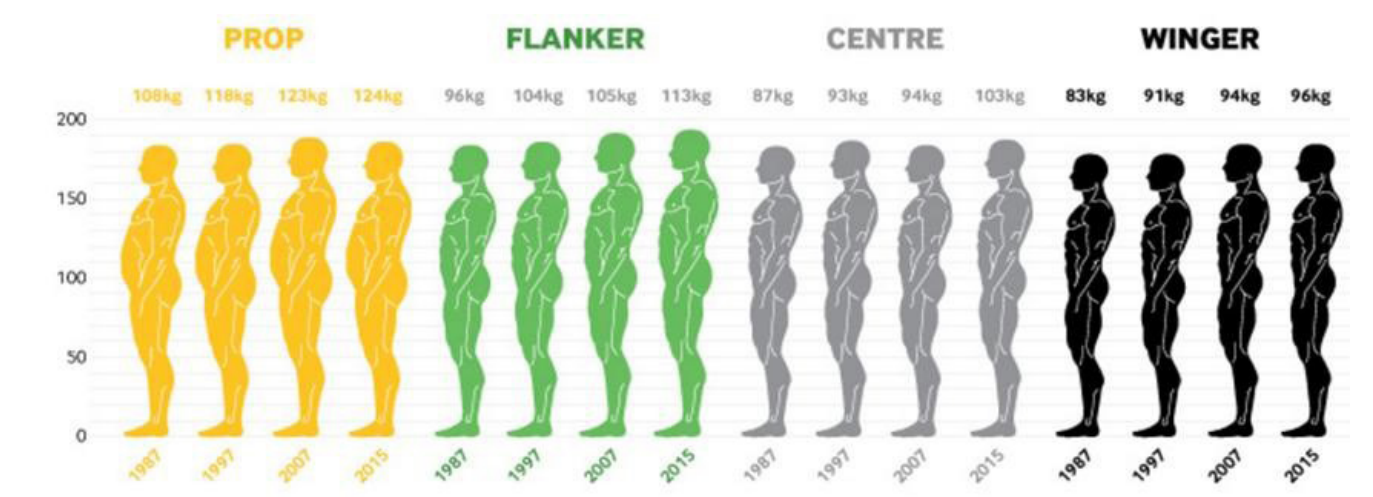

Figure 1: Changes to height and weight of positional England Rugby Internationals over time (Taken from Betway Blog [34])

Despite the high numbers of participants, literature on body (dis)satisfaction of male rugby players is limited. What exists is usually focused on females. Darko [35] stated that this lack of research may be down to the sports historical nature of being tough, masculine and its players being emotionally articulate, which could have led players to suppress their body anxieties to avoid any ramifications it may have on both their masculinity and performance. In comparison a couple of studies have drawn links to Rugby as a component of body image concern. An American study carried out by O’Dea and Rawstorne [36] which looked to identify weight gain practices, found that Rugby was highlighted specifically by a number of participants as their motivation to increase size. McCabe et al. [1] identified rugby whilst looking into the sociocultural influences on body image of Fijian, Tongan and Australian adolescents. They concluded that most Fijian boys desired an increase of upper body size, so that they were stronger and harder to tackle in rugby. Using the same target group McCabe et al. [1] looked to discover body fat loss and muscle building motivation. They identified that both Tongan and New Zealanders were very focused on achieving both muscular physiques and strength, with specific focus on the upper body. Although the majority was satisfied with their own muscles, they still desired an increase in size. Moreover rugby is the national sport of Fiji, Tonga and New Zealand which may have influenced the amount of males who desire increased muscularity specifically for rugby, which may not be similar to the UK population. However it does identify the potential desire to increase body mass and muscularity for Rugby specifically.

Although these findings focus on the upper body, it's important to consider the huge importance of lower body strength as a rugby player. Rodgers and Beesley [37] express the importance of lower body and trunk strength, and suggest that these areas should take priority over the upper body. This importance is also expressed by Cunningham et al. [38] in regards to 10 metre sprint times amongst twenty professional male rugby players. Along with Cunningham et al. [38], Bompa and Claro [39] found that leg strength and power contributed positively to speed, an essential component of team sports. Finally Russell [40] highlighted a new dimension of research regarding body satisfaction in rugby players, by discussing its variance in relation to different environments. Initial findings followed the premise that sportsmen/women have a higher body satisfaction [23], but most interestingly found that this was transient. Once outside of their sporting environment, body satisfaction levels decreased. Players may fit the performance focused ideal but lack conformity to physical attractiveness norms [40]. This study aims were to explore the prevalence of body (dis)satisfaction in terms of muscularity and body fat, and secondly to identify areas of the body that require a change (in either increase/decrease in musculature or body fat) to improve body image in comparison with that of society's ideal.

\section{Methods}

\section{Participants and Recruitment}

A sample of $n=93$ male University Undergraduate Rugby Union and League participants between the ages 18 - 25 years of age were recruited via an online social media site. Informed consent was gained from each participant and included brief study information, right to withdraw and anonymity agreement. Confidentiality of data was password protected under the security features of website SurveyMonkey.com [41] which was used to design and collect data for the survey.

\section{Data collection}

Research was quantitative by nature and came in the form of a questionnaire in three distinct parts. Firstly, the questionnaire was used to assess the current level of body satisfaction of participants using a five point Likert scale, which ranged from completely dissatisfied; somewhat dissatisfied; neither satisfied nor dissatisfied; somewhat satisfied and completely satisfied. Questions included ranking current level of body satisfaction from illustrated options provided. Secondly, participants were asked to measure their own body dimensions in relation to their ideal using a pre-validated Bodybuilders Image Grid-Original (BIG-O) scale [2]. The BIG-O figure-rating scale comprised of 30 male figures presented in both front and profile view in varying fatness along the top axis and muscularity along the lateral axis. Using the BIG-O scale, participants were asked to identify up to 3 muscle groups where they would most like to increase muscle mass and where they would most like to increase/decrease body fat. The third part of the questionnaire related to desired changes to both muscularity and fatness, but with specific focus on areas/muscle groups of 
the body. These questions were delivered in a multiple choice format, in which participants could highlight up to three separate areas or muscle groups. Participants were asked to identify up to 3 muscle groups where they would like to increase both muscle mass and body fat and would like to decrease in body fat. To help with this a sectional diagram illustrating both anterior and posterior aspects of the major muscle groups of the male body was created and used for participant reference (Figure 2).

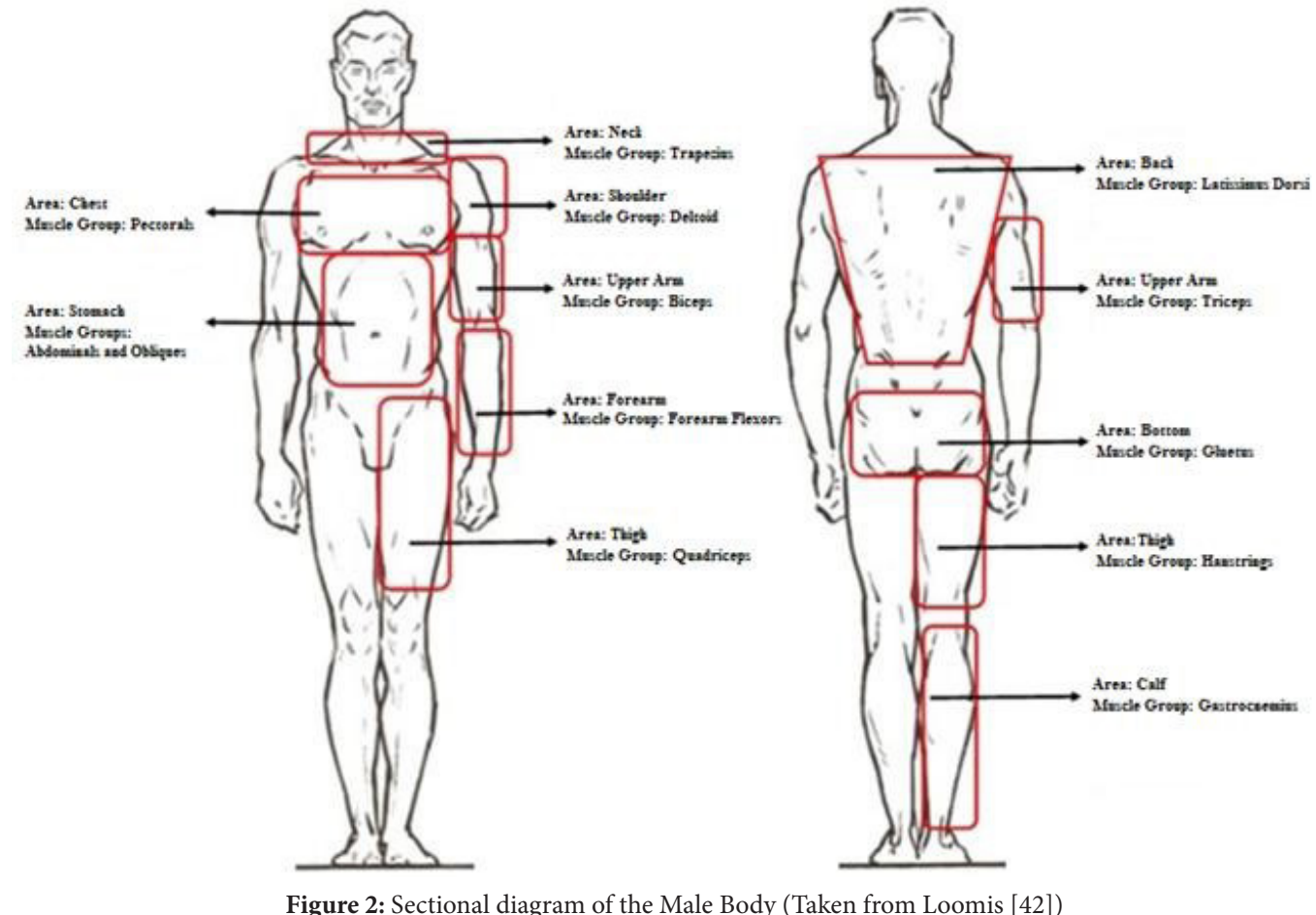

\section{Data Analysis}

The data set from the questionnaire was extracted directly from SurveyMonkey.com [41] and descriptive statistics were expressed, compared and cross analysed. Although the BIG-O figure-rating grid was used in the study to identify both current and ideal body type, the grid reference numbers (1-30) were used in contrast to its usual scale derived answer. Doing so reduced the questions complexity for participants, and this grouping method also helped for future analysis, giving a definitive answer to each question.

\section{Results and Discussion}

\section{Body Satisfaction}

Results from the questionnaire found that the majority of participants were completely or somewhat dissatisfied (49.46\%) with their current level of body satisfaction (Table 1). These results defy the idea that male athletes are largely satisfied with their bodies [24]. It is worth highlighting that the participants who deemed themselves neither satisfied nor dissatisfied made up $20.43 \%$ of the group and that if forced to choose differently may have extended or reduced this satisfaction gap.

\begin{tabular}{|c|c|c|}
\hline Potential answer & Number of participants & Overall Percentage (\%) \\
\hline Completely Dissatisfied & 4 & 4.3 \\
\hline Somewhat Dissatisfied & 42 & 45.2 \\
\hline Neither Satisfied nor Dissatisfied & 19 & 20.4 \\
\hline Somewhat Satisfied & 28 & 30.1 \\
\hline Completely Satisfied & 0 & 0.0 \\
\hline
\end{tabular}

Table 1: Breakdown of Current Body Image Satisfaction

One finding of significance was that no participant deemed themselves to be completely satisfied with their body. This zero percentage may be a result of a few possible explanations. Firstly, it could be assumed that the media's portrayal of the masculine man has created unrealistic body aspirations [11]. Secondly perhaps, the participants are comparing themselves to the increasingly muscular rugby ideal, a suggestion made by Olds [32]. Thirdly, the participants did not feel comfortable in stating that they thought their body is perfect. Or it's quite possible that our non-elite players "know" that they are not as big, fast or strong as their elite counterparts and therefore express this with below "perfect" evaluations of their bodies. In any case an increase in size is often seen each year, placing the average male rugby player further away from both the rugby and societal ideal body [28]. 


\section{Current and Desired Physique}

With the help of the Body Builder Image Grid (BIG-O) [2], the variation of current body types held by the target group were identified. Participant's varied in body type from image number 3 to image number 26, but produced a median of image 14. The distribution of current body ideals is better portrayed visually in Figure 3. This variation in body type can partly be explained by the body compositional differences required by specific playing positions in rugby. For instance, playing positions such as the 'prop' often require a heavier and larger body (image number 23 and 26) compared to that of a 'winger' often seen with a smaller body (image 7 and 8 ).
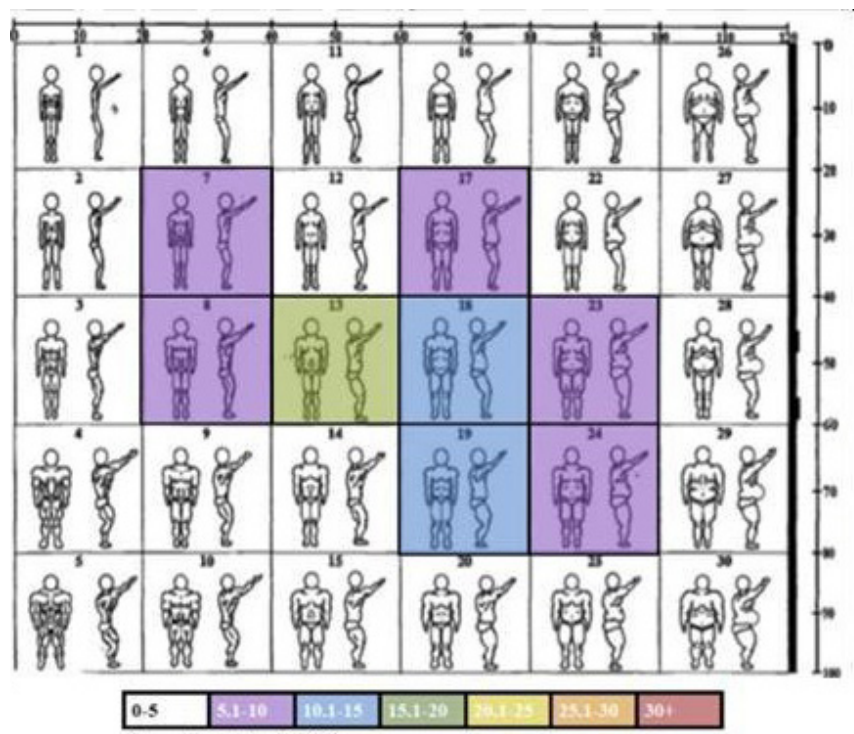

Percentage Scale (\%)

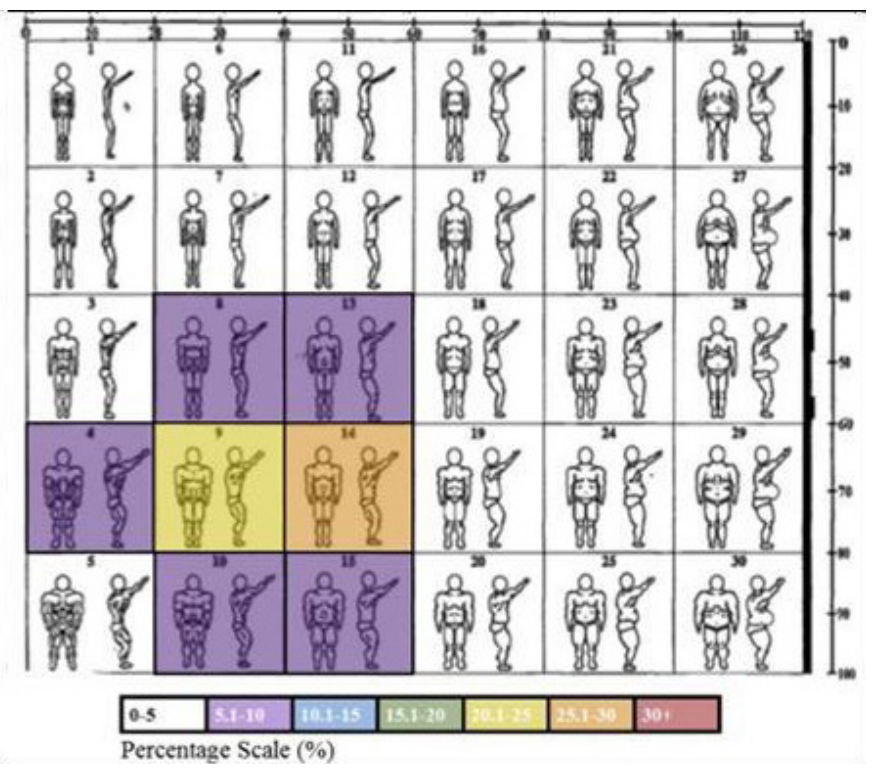

Percentage Scale (\%)

Figure 3: Current (left) and Desired (right) Physique colour coded participant distribution

Participants as a whole highlighted a range of 12 separate images as ideals compared to the 19 identified in relation to current body. Responses showed a more condensed correlation toward the median image number 14, suggesting that the participant's wanted to be leaner and more muscular. On average participants wished to increase their muscularity by one image and reduce their body fat by one image in accordance with the BIG-O scaling. This diagonal movement towards the leanest, most muscular image indicates that the participants have a clear intention of following society's muscular ideal $[43,44]$. Of course this change in body shape could just as likely be desired for increased rugby performance, especially given the physiological demands of today's game [33].

\section{Most common areas for increased muscle mass}

Participants rated the pectorals, abdominal and deltoids within the top five areas for muscular increase (Figure 4). These findings can be perceived as an assertion of muscularity. Furthermore, in line with Franzoi and Shields [20] where they suggested that upper body strength makes up one third of male body image, and secondly, Hoyt and Kogan [15] who found that chest, upper arm and abdominals received the most media attention.

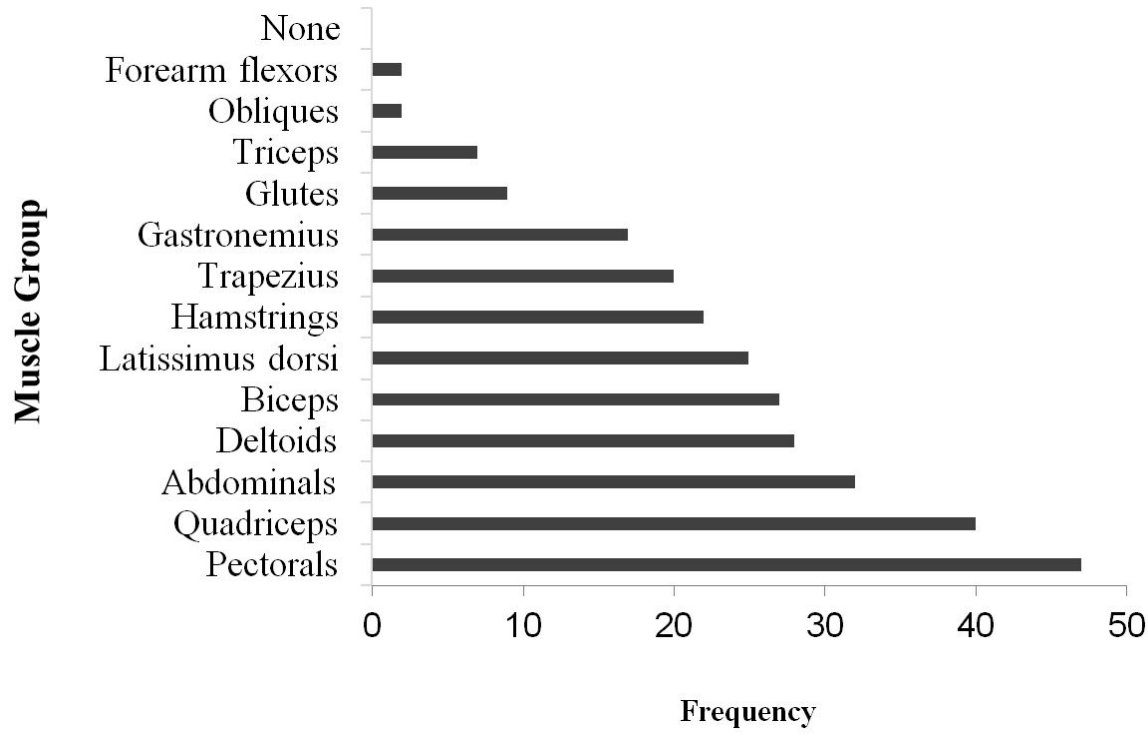

Figure 4: Frequency breakdown of muscle groups chosen for increased muscularity 
The quadriceps muscles were ranked second highest in terms of desired increase of muscle mass. Having a lower limb muscle group ranked so highly is inconsistent to the general population [3]. However given that the majority of participant's (43.1\%) desire for increased muscularity is in the quadriceps, this identifies the potential focus on performance and could explain the level of importance placed on the lower body.

\section{Desired changes to body fat}

Participants were asked to identify areas of the body in which they wanted to increase body fat stores, and results found that $88.44 \%$ of participants did not want an increase in body fat stores. Remaining participants who desired an increase in body fat had inconclusive findings, with the calf and gluteal area ranking with $8.62 \%$ and $6.51 \%$ respectively. These results indicate that the majority of participants have no desire to increase their fat stores and are consistent with the findings of Leit et al. [13] who discovered that the that the majority of males aimed for a leaner physique.

In relation to a reduction in body fat results were contrasting. $86.41 \%$ of participants wished to reduce body fat in at least one area. This dramatic aspiration to reduce body fat, suggests that the target audience were not satisfied with their overall body fat stores. Figure 5 indicates that the stomach area is of most concern for the male rugby player when it comes to reducing fat stores. According to The Huffington Post [21] 54.44\% of average males disliked their stomach, thus highlighting the prevalence of dissatisfaction of the stomach amongst both the general population of males and the 18-25 year old rugby player. With majority of body fat being stored in the stomach, chest and back, a desire for reduction in these areas is unsurprising, especially when a defined stomach and chest are given great attention in the media [15].

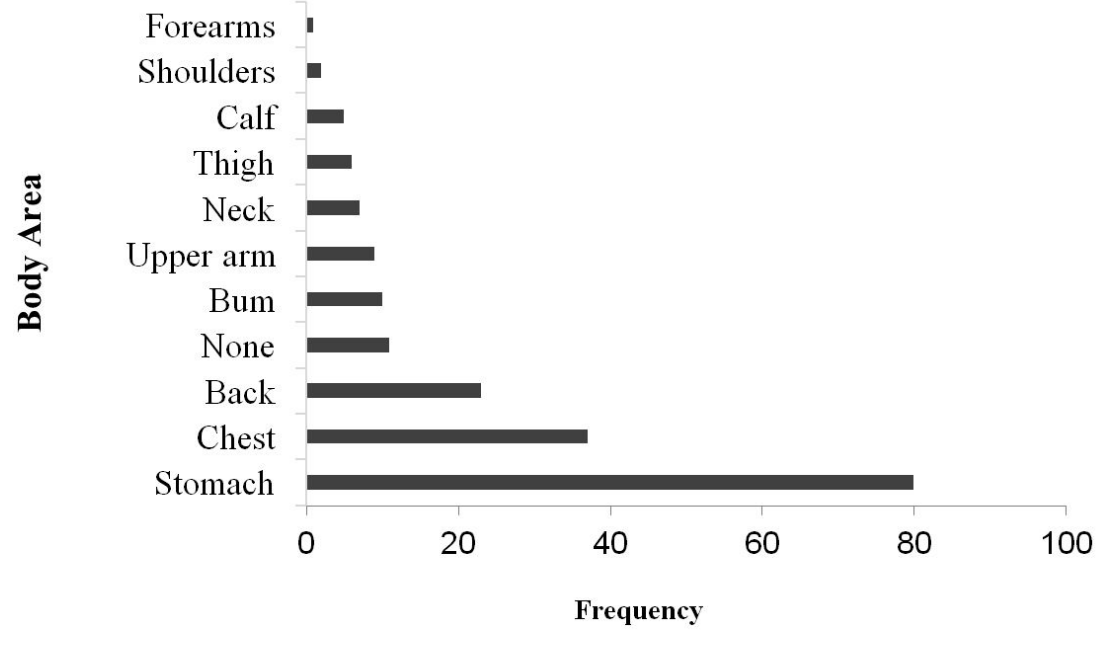

Figure 5: Frequency breakdown of body areas chosen for reduced body fat

\section{Overall body satisfaction on desired changes to both muscularity and body fat}

Participants were categorised into two groups in relation to whether they were satisfied or dissatisfied with their current body image in relation to muscularity and body fat. Participants whom answered either completely or somewhat satisfied $(n=30)$ were cross analysed against those who answered completely or somewhat dissatisfied $(n=42)$ to gain an understanding of the importance of a healthy body image and aspect that may build it. The participants which answered neither satisfied nor dissatisfied were left out of the data set. A comparison between the degrees of change to muscularity and body fat was carried out by Body Builder Image Grid (BIG-O) scaling giving a +1 image increase (average image 13.7) and -1 image decrease (average image 16.3) in either muscularity or body fat.

Statistical differences were found in relation to muscularity and body fat, with aspiration for both increased muscularity (1.26 $\pm 1.64)$ and reduced body fat $(-1.07 \pm 1.24)$ shown in the dissatisfied group. In contrast the satisfied group identified increased muscularity $(0.92 \pm 0.72)$ and reduced body fat $(-0.87 \pm 0.97)$. Results suggest that the dissatisfied group carry more body fat and less musculature than those who are satisfied. These results concur with previous research that identified the desire for decreased body fat [18] and for increased musculature within males [19]. Significant differences were also discovered in the muscle groups targeted for increased muscular size. The drive to improve abdominal muscularity was stronger in the dissatisfied (12.71\%) in comparison to those satisfied (6.67\%). The abdominals is an area frequently targeted by both the media and in relation to attractiveness, so possibly indicating that those dissatisfied are aiming for society's ideal rather than a sporting ideal [15;13]. In addition, our satisfied participants had a greater desire to improve the hamstrings (satisfied $11.11 \%$ and dissatisfied $7.14 \%$ ) and gastrocnemius (satisfied $7.78 \%$ and dissatisfied 3.17\%). Both these areas are vital for rugby performance and specifically in regards to sprint speed [38]. Findings of this nature supplement the argument that a sporting ideal creates a more positive outlook on body image than societies. 


\section{Conclusion}

Although body image is a complex and easily manipulated premise, correlations can be seen between those with a positive body image and areas associated with performance. It was evident that male rugby players did experience substantial levels of body dissatisfaction, with the majority (49.46\%) dissatisfied with their current body compared to being satisfied (30.11\%). Furthermore, $86.41 \%$ desired a reduction in body fat and $100 \%$ wanted to increase muscularity. Many of the prominent areas highlighted for muscular increase were consistent with that of society's ideal including the chest, abdominals and deltoids, suggesting that male rugby player's value society's ideal over a performance ideal. Whereas those satisfied with their body were more likely to place emphasis on areas of the body associated with rugby performance, suggesting that a performance based outlook on ideal improves overall body satisfaction, consistent with research from McCabe and Riciardelli [5].

Within this study, the researchers were mindful that the participants were most likely to compare their body to that of the performance ideal, rather than those in a societal environment of an attractive heterosexual male. Recommendations for further research could allow the comparison of body (dis)satisfaction between those with a performance focus and those focused on societies ideal. Furthermore, to recruit varying rugby playing standards, such as international and club level players and compare if there are differences in body (dis)satisfaction.

\section{References}

1. McCabe MP, Fotu K, Dewes O (2011) Body image, weight loss and muscle building among Tongan adolescents in Tonga and New Zealand. J Health Psychol 16: 1101-8.

2. Hildebrandt T, Langenbucher J, Schlundt DG (2004) Muscularity concerns among men: development of attitudinal and perceptual measures. Body Image 1: $169-81$.

3. Grogan S (2007) Body Image: Understanding body dissatisfaction in men, women and children ( $2^{\text {nd }}$ Edn) New York, NY: Taylor \& Francis, USA.

4. Myers PN, Biocca FA (1992) The elastic body image: The effect of television advertising and programming on body image distortions in young women. J Communication 42: 108-33.

5. McCabe MP, Ricciardelli LA (2004) Body image dissatisfaction among males across the lifespan: A review of past literature. J Psychosom Res 56: 675-85.

6. All Parliament Group on Body Image (2012) Reflections on body image All Parliament Group on Body Image and Central YMCA.

7. Burrowes N (2013) Body image - A rapid evidence assessment of the literature (Government Equalities Office) London: Department for Culture, Media and Sport, UK.

8. Leit RA, Gray JJ, Pope HG (2002) The media’s representation of the ideal male body: A cause for muscle dysmorphia? Int J Eat Disord 31: 334-8.

9. Cash TF, Pruzinsky T (2002) Media influences on body image development. In: Body image: A handbook of theory, Research, and clinical practice, New York: Guilford Press, USA.

10. Dominick JR, Fletcher JE (1985) Television and enculturation In: Broadcasting research methods, Boston: Allyn \& Bacon, USA.

11. Bordo S (2003) Unbearable weight: Feminism, Western culture, and the body (10 ${ }^{\text {th }}$ Edn) Berkeley, CA: University of California Press.

12. Baghurst T, Hollander DB, Nardella B, Haff GG (2006) Change in sociocultural ideal male physique: An examination of past and present action figures. Body Image 3: 87-91.

13. Leit RA, Pope HG, Gray JJ (2001) Cultural expectations of muscularity in men: The evolution of Playgirl centerfolds. Int J Eat Disord 29: 90-3.

14. Lanzieri N, Cook BJ (2013) Examination of muscularity and body fat depictions in magazines that target heterosexual and gay men. Body Image 10: 251-4.

15. Hoyt WD, Kogan LR (2001) Satisfaction with body image and peer relationships for males and females in a college environment. Sex Roles 45: 199-215.

16. Clifford E (1971) Body satisfaction in adolescence. Perceptual and Motor skills 33: 119-25.

17. Hill AJ, Oliver S, Rogers PJ (1992) Eating in the adult world: The rise of dieting in childhood and adolescents. Br J Clin Psychol 31: 95-105.

18. Furnham A, Calnan A (1998) Eating disturbances, self-esteem, reasons for exercising and body weight dissatisfaction in adolescent males. Eur Eating Disorders Rev 6: 58-72.

19. Pope HG, Phillips KA, Olivardia R (2000) The Adonis Complex: The secret crisis of male body obsession. New York: Free Press, USA.

20. Franzoi SL, Shields SA (1984) The Body Esteem Scale: Multidimensional structure and sex differences in a college population. J Pers Assess 48: 173-8.

21. The Huffington Post (2015) Male Body Image Report Shows Half OF British Men Suffer Low Body Confidence, UK.

22. Ricciardelli LA, McCabe MP, Ridge D (2006) The Construction of the Adolescent Male Body through Sport. J Health Psychol 11: 577-87.

23. Hausenblas HA, Symons Downs D (2001) Comparison of body image between athletes and non athletes: A meta-analytic review. J Appli Sport Psychol 13: 323-39.

24. Krane V, Greenleaf C, Henry A, Bonner K (2005) Sporting bodies: Exploring male athletes' body images. The Association for the Advancement of Applied Sport Psychology Conference.

25. Arroyo M, Gonzalez-de-Suso JM, Sanchez C, Ansotegui L, Rocandio AM (2008) Body image and body composition: comparisons of young male elite soccer players and controls. Int J Sport Nutr Exerc Metab 18: 628-38.

26. Galli N, Reel JJ (2009) Adonis or Hephaestus? Exploring body image in male athletes. Psychol of Men Masculinity 10: 95.

27. Sport England (2016) People engage in different sports in different ways, UK.

28. Pringle R, Markula P (2005) No Pain Is Sane After All: A Foucauldian Analysis of Masculinities and Men's Rugby Experiences of Fear, Pain, and Pleasure. Sociology of Sport Journal 22: 472-97.

29. Trenberth L, Collins C (1994) Media sport. In: Sport management in New Zealand: An introduction, Palmerston North, N.Z. : Dunmore Press, New Zealand.

30. Worth H, Paris A, Allen L (2002) Living the contradictions: A Foucauldian examination of my youthful rugby experiences In: Life of Brian: Masculinities, sexualities and health in New Zealand, Dunedin, N.Z. : University of Otago Press, New Zealand. 
31. Mangan JA (1981) Athleticism in the Victorian and Edwardian Public School: The Emergence and Consolidation of an Educational Ideology. Cambridge: Cambridge University Press, UK.

32. Olds T (2001) The evolution of physique in male rugby union players in the twentieth century. J Sports Sci 19: 253-62.

33. Sedeaud A, Marc A, Schipman J, Tafflet M, Hager JP, et al. (2012) How they won Rugby World Cup through height, mass and collective experience. Br J Sports Med 46: 10.1136/bjsports-2011-090506.

34. Betway Blog (2016) The remarkable evolution of the modern day rugby player, UK.

35. Darko N (2012) Rugby union men: body concerns (Doctoral dissertation). Loughborough University (unpublished), UK.

36. O’Dea JA, Rawstorne PR (2001) Male adolescents identify their weight gain practices, reasons for desired weight gain, and sources of weight gain information. J Am Diet Assoc 101: 105-7.

37. Rodgers T, Beesley R (2006) Fitness for Rugby League.

38. Cunningham DJ, West DJ, Owen NJ, Shearer DA, Finn CV, et al. (2013) Strength and power predictors of sprinting performance in professional rugby players. J Sports Med Phys Fitness 53: 105-11.

39. Bompa T, Claro F (2009) Periodization in rugby, Aachen: Meyer \& Meyer, Germany.

40. Russell KM (2004) On versus off the pitch: The transiency of body satisfaction among female rugby players, cricketers, and netballers. Sex roles 51: 561-74.

41. Survey Monkey (2016) UK.

42. Loomis A (1943) Figure drawing for all it's worth. New York: The Viking Press, USA.

43. Drewonski A, Yee DK (1987) Men and body image: are males satisfied with their body weight? Psychosom Med 49: 626-34.

44. Silberstein LR, Striegal-Moore RH, Timko C, Rodin J (1988) Behavioral and psychological implications of body dissatisfaction: do men and women differ? Sex Roles 19: 219-32.

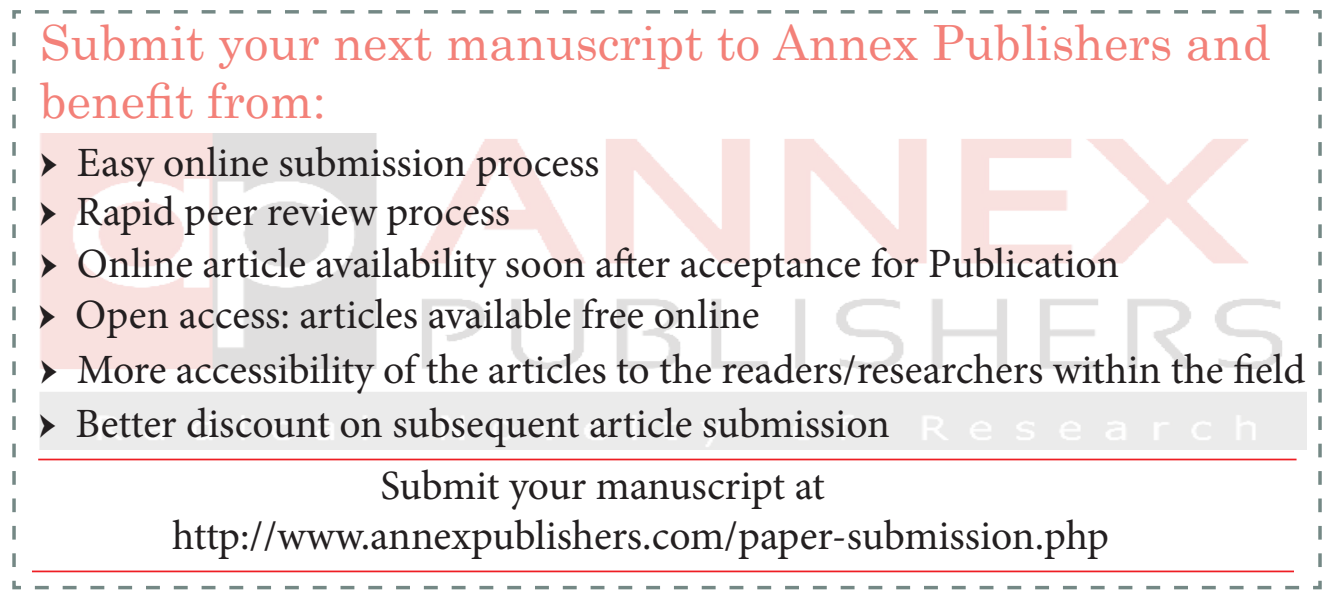

